\title{
Predictors of Employability of the Bachelor of Secondary Education Major in Mathematics Graduates
}

\author{
${ }^{1}$ Alcher J. Arpilleda, ${ }^{2}$ Anthony Mark Joseph M. Manile \& ${ }^{3}$ Pacita I. Soringa \\ ${ }^{1,2}$ St. Paul University Surigao, Philippines \\ ${ }^{3}$ St. Joseph Learning Center, Philippines \\ Ialcher.arpilleda@spus.edu.ph \\ 2amj062792@gmail.com \\ 3pacitasoringa@yahoo.com
}

\begin{abstract}
The goal of every program provided by a school or university is to make it more responsive to the needs of fast-changing employment demands. This goal also entails enhancing the students' skills to be prepared for their future jobs. This study identified the predictors of employability of the Bachelor of Secondary Education Major in Mathematics graduates of St. Paul University Surigao Academic Year 2005-2015. Descriptive survey research was employed using a researcher-made questionnaire encompassing the personal information, employment status, and exit skills with seven identified subparts. The questionnaire elicited employability through the skills of $81.82 \%$ of the participants. Utilizing the employment status variables and the exit skills, Linear Regression Analysis extracted the predictors of employability. The findings revealed that the exit skills of the graduates are the predictors of employability. Thus, the school should create programs and activities which enhance the students' skills, particularly the predictors of employability identified in this study.
\end{abstract}

Keywords: employability, employment, exit skills, predictors

\section{Introduction}

In the status-quo of education, graduates' employment is the basis of many universities or higher education institutions to evaluate on how their program performs in creating their students fruitful and productive in their field (Smith et al., 2000 as cited by Boholano, 2012).

Knight and Yorke (2003) defined employability as an assemblage of achievements, skills, understanding, and personal attributes that will support graduates to attain employment and be successful in their selected profession. Meanwhile, skills help one acquire employment, but achievements prove that one is able to implement his or her skills in practice (Carr, 2016). Cardona and Andres (2014) argued that skills are able to organize part of the context of being employable.

In most cases, students have enrolled in any higher institution to acquire new knowledge and skills applicable in the workplace. The responsibility of University or College in training students is not limited to imparting academic skills but also building their character as members of society's workforce.

After finishing the degree in education, graduates should prepare themselves for the Licensure Examination for Teachers (LET) in most cases. However, other graduates frequently look for other jobs, domestic or international, to possess experience before the teaching career or before obtaining the LET. The institution has no more control or contact with the graduates regarding their employment status except when it is established graduates' social gatherings. 
Tracer studies were conducted before by the College of Teacher Education Faculty to determine the LET performance and the employment rate of the graduates of education faculty. In May 2006, a study on LET Performance of SPU Surigao Education Graduates from 2000 to 2005 was performed. In August 2009, a study on the LET Performance and Employment Rate of Education Graduates from 2000 to 2008 of St. Paul University Surigao was also administered.

However, the current tracer study was conducted to trace the predictors of employability of Bachelor of Secondary Education Major in Mathematics graduates of St. Paul University Surigao A.Y. 2005-2015. Particularly, the objective is to determine the graduates' profiles, employment status, and exit skills.

The findings of the present study provide as the basis of the researcher to enhance or update the curricula of the Bachelor of Secondary Education- Mathematics program to be responsive to the needs of fast-changing employment demands and also to improve the skills of the students for them to be prepared in their future jobs. This study is also deemed necessary to unleash the skills of mathematics teachers further to uphold enhancing the mathematical performance of the Filipinos as the students lagged behind other countries in the Trends in International Mathematics and Science Study 2019 (TIMSS), an international assessment for mathematics and science for grade 4.

\section{Conceptual Framework of the Study}

The study was anchored on the concept of Cardona and Andres (2014) that despite the graduates' status, the prior challenge is not only that they are employed or employable but also that their employment best utilizes their education and that their skills generate part the context of being employable. They also explained that the skills of the graduates are able to build part of the context of being employable. Then, the researchers perceived the Program Outcomes of Bachelor of Secondary Education as the basis for the skills of the education graduates.

Cardona and Andres (2014) stated that leadership, communication, information technology, problem-solving, critical thinking, human relations, creativity, decision-making, technical, and research are able to establish part of the context of being employable.

Furthermore, the Program Outcomes (PO) of Bachelor of Secondary Education, as stated in the university handbook, also discusses about skills like communication, numeracy, critical thinking, leadership through facilitating learning, problem-solving, planning and decision making, creativity, innovativeness, human relations through instilling Filipino cultural values, and research skills.

Based on the two sources, the researchers considered the following skills of graduates:

Communication. It refers to the skills of the respondents in dealing with and communicating with the people around them. It associates writing, speaking, and listening. As explained in the College of Teacher Education Program Outcome 1 (CTEPO1), graduates are equipped with a basic and higher level of literacy, communication, and learning skills required for higher learning.

Leadership. It refers to the respondents' skills in managing and supervising a team and cooperating in every task that a group should perform. As stated in CTEPO2, leadership skill is employed in demonstrating and facilitating the learning processes in their students. 
Decision Making. It refers to the respondents' skills in planning a certain activity and making a decision towards the implementation of the plan. As to the context of teachers, as specified in CTEPO4, graduates demonstrate the acquired teaching process skills, encompassing curriculum development, lesson planning, materials development, educational assessment, and teaching approaches. These teaching process skills involve decision-making.

Problem Solving. It refers to the respondents' skills in handling the problems which occurs along his/her working journey. As presented in CTEPO1, graduates are equipped with a basic and higher level of critical thinking required for higher learning. Problem-solving skill is also essential in lesson planning, educational assessment, as stipulated in CTEPO4.

Creativity. It refers to the respondents' skills in creating something new beneficial for the betterment of himself/herself, his/her workplace, and the entire community. It is declared in CTEPO9 that graduates are able to create, innovate, simulate, and evaluate in enhancing student learning.

Human relations. It refers to the respondents' skills in associating other people and interacting with them in times of work. It is explained in CTEPO11 that graduates act upon Filipino cultural values in the exemplification of the values of discipline, honesty, social responsibility, thrift, hard work, compassion, availability, accountability, teamwork, and respect for elders, wise conservation, and utilization of natural resources, with Christ as a model.

Research. It refers to the respondents' skills in conducting an investigation or research study which helps improve the workplace or the employment status of the respondent. It is also stated in CTEPO12 that graduates should conduct research and utilize results in response to the demands of 21 st-century teaching and learning.

\section{Methods}

\section{Research Design}

The study employed a quantitative descriptive design using a survey technique to allow the researcher to obtain quantifiable information on the predictors of employability of the BSEdMathematics Graduates (2005-2015) of St. Paul University Surigao. The design was considered appropriate because it is probably the best method available to collect data from tracing the employment status and exit skills that could predict the employability of the SPU Surigao BSEd Mathematics Graduates.

\section{Participants}

The participants of this study were the graduates of Bachelor of Secondary Education Major in Mathematics of St. Paul University Surigao from 2005 to 2015. The researchers considered the year 2005 as the start of the scope of participants because, in that year, the first batch graduated from St. Paul University Surigao as it transitioned from San Nicolas College.

\section{Instrument}

The main instrument administered to solicit information was a researcher-designed questionnaire, a self-assessment survey wherein the participants provided personal and 
professional information and rate themselves in terms of their skills. The tool is appropriate as the participants understood very well of their performance regarding the skills encompassing in the study.

The questionnaire consisted of three (3) parts. Part 1 is the profile of the respondents comprising of the name, age, sex, year graduated, LET Performance, current and home address, contact number, and e-mail address. Part 2 of the questionnaire is on the respondents' employment status, encompassing present work, employment type, employer type, company/institution/school name, and workplace. Part 3 of the questionnaire is on the skills of the graduates, incorporating communication, leadership, decision making, problem-solving, creativity, human relations, and research. The researchers were able to formulate the indicators for each skill through the concepts provided by Cardona \& Andres (2014), program outcomes of the Bachelor of Secondary Education, and the work ethics presented in the University Student Handbook, 2015 Edition. Three experts validated the questionnaire for content validity.

\section{Data Gathering Procedure}

The researchers provide a letter of request to the dean for approval to conduct the study. Upon approval, the researchers administered the questionnaire to the respondents. Considering that the respondents were not living in the same place, the researchers sent the questionnaires through social media (Facebook, Yahoo, or Gmail). After the participants answered the questionnaire, they sent it back to the researchers. The data were collected, tallied, analyzed, and interpreted the result.

\section{Data Analysis}

In tracing the predictors of employability of the BSEd Mathematics graduates of St. Paul University Surigao, the researchers employed several statistical tools to examine the data of the study. The first one is frequency count and percentage distribution, which were utilized to describe the participants' profile and employment status. We also administered descriptive statistics in the form of mean and standard deviation, to determine the skills of the graduates. The following were the basis for interpretation of data:

Table 1

Basis for Data Interpretation

\begin{tabular}{ccll}
\hline Scale & Range & Verbal Interpretation & Qualitative Description \\
\hline 4 & $3.25-4.00$ & Strongly Agree & Very Skillful \\
3 & $2.50-3.24$ & Agree & Skillful \\
2 & $1.75-2.49$ & Disagree & Less Skillful \\
1 & $1.00-1.74$ & Strongly Disagree & Least Skillful \\
\hline
\end{tabular}

Then, we employed Pearson Product Moment Correlation of Coefficient, to calculate the significance of the relationship between the exit skills and each variable of the participants' profile; age and LET Performance scores, as well as the significance of the relationship between the graduates' skills and their employment status as to the work, employment type, and employer type. The variables were coded into numerical data. For determining the 
significance of the relationship between exit skills and the variable sex, the researcher employed Point-Biserial Coefficient of Correlation. Last but not least, Multiple Linear Regression Analysis was administered to determine the graduates' exit skills predictors in which the relationship between one dependent variable and two or more independent variables was examined. It generates important predictors between one or more independent variables and the dependent variable (Frost, 2013). The predictors were the exit skills of the graduates, considered as independent variables, while the employment characteristics are the dependent variables. Further, the forward Stepwise Method was used because it selects a subset of predictor variables for the final model. It is best implemented to obtain the best predictor and apply all possible algorithms to the variables in a provided subset. It is tractable, and it provides a good sequence of a model (Wuencsch, 2014).

\section{Results and Discussion}

\section{Profile of the BSEd Math Graduates}

Table 2 displays the profile of the Bachelor of Secondary Education major in Mathematics graduates in terms of age, sex, and LET Performance.

Table 2

Profile of the BSEd Math Graduates

\begin{tabular}{lll}
\hline Categories & $\mathrm{f}(27)$ & $\%$ \\
\hline Age & 6 & \\
20 -24 years old & 62.22 \\
25-28 years old & 11 & 40.74 \\
29-32 years old & 8 & 29.63 \\
33-36 years old & 2 & 7.41 \\
\hline Sex & & \\
Male & 9 & 33.33 \\
Female & 18 & 66.67 \\
\hline LET Performance & & \\
Passed & 21 & 77.78 \\
Failed & 1 & 3.70 \\
Not yet enrolled & 5 & 18.52 \\
\hline
\end{tabular}

As to age, of the 27 participants, 6 or $22.22 \%$ are $20-24$ years old; 11 or $40.74 \%$ are $25-28$ years old; 8 or $29.63 \%$ are $29-32$ years old, and 2 or $7.41 \%$ are $33-36$ years old. It means that most of the graduates answering the survey questionnaire were 25 to 28 years old. Based on the data collected, the age with the highest number of graduates is 32 years old and was all from batch 2005, considering that 2005 owns the highest number of graduates. As presented in the table, the age bracket with the highest frequency is 25-28 years old, and this bracket is composed of the graduates of batches 2009-2015. Among these batches, batch 2012 possesses the highest frequency with three graduates. 
Regarding sex, of the 27 participants, 9 or $33.33 \%$ are males, and 18 or $66.67 \%$ are females. In this study, more female participants graduated and answered the survey questionnaire than males. Based on the data obtained, batch 2005 owns the highest number of female graduates with five graduates.

Regarding the LET Performance, of the 27 participants, 21 or $77.78 \%$ passed the Licensure Examination for Teachers; 1 or $3.70 \%$ failed, and 5 or $18.52 \%$ of the participants have not yet enrolled the LET. Based on the data collected, one failed in the Licensure Examination for Teachers and was from batch 2009, while those who have not taken the LET yet were one from batch 2015, 2011, 2013, and two from batch 2005. Other graduates who were part of the study already passed the LET.

As the data display, batch 2005 has the highest frequency in every profile variable, and it is true because it has the highest number of graduates with six participants.

\section{Employment Status of the Graduates}

Table 3 presents the employment status of the graduates as to the present work, employment type, and employer type.

Table 3

Employment Status of the Graduates

\begin{tabular}{lcc}
\hline & $\mathrm{f}(27)$ & $\%$ \\
\hline Work & 22 & 81.48 \\
Teacher & 1 & 3.70 \\
Tele sales Adviser & 1 & 3.70 \\
Administrative Assistant & 1 & 3.70 \\
Office Secretary & 1 & 3.70 \\
Domestic Helper & 1 & 3.70 \\
Army Captain & & \\
Employment Type & 17 & 62.96 \\
$\quad$ Permanent & 2 & 7.41 \\
Casual & 6 & 22.22 \\
Temporary & 2 & 7.41 \\
$\quad$ Probationary & & \\
Employer Type & 16 & 59.26 \\
Public & 11 & 40.74 \\
Private & & \\
\hline
\end{tabular}

In terms of present work, of the 27 participants, 22 or $81.48 \%$ are teachers; 1 or $3.70 \%$ is a Tele sales adviser, administrative assistant, office secretary, domestic helper, and army captain. Most of the participants are teachers. Most of the participants possess their work which matches the undergraduate course they have enrolled. From the data collected, most of the participants are recently teaching with batch 2005 as the batch with the highest frequency with four graduates, while the rest of the participants possess different works and were from batches 2005, 2011, 2013, and 2015.

As to the employment type, of the 27 participants, 17 or $62.96 \%$ are permanent; 2 or $7.41 \%$ are casual and probationary; 6 or $22.22 \%$ are temporary. It implies that most of the participants 
are permanent in their employment. Based on the data collected, batch 2005 owns the highest number of permanently employed graduates with five graduates.

Regarding the employer type, of the 27 participants, 16 or $59.26 \%$ are working with a public employer, while 11 or $40.74 \%$ are working with a private employer. It indicates that most of the participants are employed in a public institution or company. Based on the data, batch 2005 owns the highest number of graduates employed in a public institution with five graduates.

As the data present, batch 2005 has the highest frequency in every variable under the employment status, and it is true because 2005 possesses the highest number of graduates with six participants.

\section{Exit Skills of Graduates}

Table 4 displays the exit skills of the graduates as to communication skills, leadership skills, decision making, problem-solving, creativity, human relations, and research.

\section{Table 4}

\section{Exit Skills of the Graduates}

\begin{tabular}{|c|c|c|c|}
\hline Skills & $\underline{\mathrm{M}}$ & SD & QD \\
\hline \multicolumn{4}{|l|}{ 1. Communication Skills } \\
\hline - I know how to write communication letters (memorandum, business letter, etc.) & 3.31 & 0.55 & VS \\
\hline - When I talk with someone in the workplace, I use English or Filipino. & 3.08 & 0.69 & S \\
\hline $\begin{array}{l}\text { - When someone is talking, I listen attentively to what he/she is saying to hear the } \\
\text { point of the message. }\end{array}$ & 3.73 & 0.45 & VS \\
\hline $\begin{array}{l}\text { - When I speak or listen, I look into the eyes of the person I am conversing with to } \\
\text { produce the interaction more successful. }\end{array}$ & 3.65 & 0.49 & VS \\
\hline - I attempt to visualize what other people say so that I know how to respond. & 3.65 & 0.49 & VS \\
\hline Mean: & 3.48 & 0.53 & VS \\
\hline \multicolumn{4}{|l|}{ 2. Leadership Skills } \\
\hline - I empower people by sharing leadership responsibilities. & 3.50 & 0.51 & VS \\
\hline - I inspire people to achieve set goals. & 3.50 & 0.51 & VS \\
\hline $\begin{array}{l}\text { - I build and maintain collaborative partnerships for the improvement of my } \\
\text { workplace and the community. }\end{array}$ & 3.69 & 0.47 & VS \\
\hline - I challenge people to take risks with tranquil daring. & 3.23 & 0.65 & S \\
\hline - I manage my works, operations, and resources for the effectiveness and efficiency. & 3.69 & 0.47 & VS \\
\hline Mean: & 3.52 & 0.52 & VS \\
\hline \multicolumn{4}{|l|}{ 3. Decision Making } \\
\hline - I implement a well-defined process to structure my decisions. & 3.42 & 0.58 & VS \\
\hline $\begin{array}{l}\text { - I take the time required to select the best decision-making tool for each specific } \\
\text { decision. }\end{array}$ & 3.35 & 0.63 & VS \\
\hline - I consider a variety of potential solutions before I make my decision. & 3.54 & 0.51 & VS \\
\hline - I observe various planning practices to make sound decisions. & 3.58 & 0.50 & VS \\
\hline $\begin{array}{l}\text { - I determine the most important factors to the decision and use such to evaluate my } \\
\text { choices. }\end{array}$ & 3.62 & 0.50 & VS \\
\hline Mean: & 3.50 & 0.54 & VS \\
\hline \multicolumn{4}{|l|}{ 4. Problem Solving } \\
\hline - I take time to inv & 3.81 & 0.40 & VS \\
\hline
\end{tabular}


- I am flexible in which I can easily adapt and adjust when a problem arises and stays focus to think well of the solution.

- I maintain an attitude of openness to ideas that could help solve the problem.

- I attempt to look at problems from different perspectives and generate multiple solutions.

- I handle problems with utmost prudence.

5. Creativity

- I provide new ideas or concepts and go beyond conditioned setups.

- I enable self-discovery.

- I optimize and share resources.

- I create and innovate alternative strategies for the improvement of the institution. 3.420 .58 VS

- I consult others to enhance knowledge and wisdom to be able to create new things. 3.650 .49 VS Mean:

6. Human Relations

- I share a healthy rapport with the people around me.

- I respect the social decorum of the group.

- I treat and value individuals with dignity as children of God.

- I feel comfortable with different kinds of people in my workplace.

- I promote positive relationships with compassion and tenderness.

7. Research

- I continue my learning by enduring with the new research and studies that could help enhance my workplace.

- I continue to pursue information to obtain a broad perspective.

- I conduct research and utilize the results in response to the demands of society.

- I learn how to process events and experiences as means to perfection.

- I critically evaluate data to produce the information needed.

Mean:

Scale Range

$4 \quad 3.25-4.00$

$32.50-3.24$

$2 \quad 1.75-2.49$

$1 \quad 1.00-1.74$
Verbal Interpretation (VI)

Strongly Agree

Agree

Disagree

Strongly Disagree

As to communication skills, among the five indicators, the item when someone is talking, I listen attentively to what he/she is saying to clearly hear the point of the message $(\underline{M}=3.73$, $\mathrm{SD}=0.45$ ) owns the highest mean and is illustrated as Very Skillful, while the item with the lowest mean is when I talk with someone in the workplace, I use English or Filipino $(\underline{\mathrm{M}}=3.08$, $\mathrm{SD}=0.69)$ which is characterized as Skillful. On average, communication skills $(\underline{\mathrm{M}}=3.48$, $\mathrm{SD}=0.53$ ) are described as Very Skillful. It indicates that the graduates are well-trained in communication skills except employing English or Filipino in the workplace.

As to leadership skills, among the five indicators, the items with the highest means are $I$ build and maintain collaborative partnerships for the improvement of my workplace and the community; I manage my works, operations, and resources for the effectiveness and efficiency $(\underline{\mathrm{M}}=3.69, \mathrm{SD}=0.47)$ and are characterized as Very Skillful, while the item I challenge people to take risks with tranquil daring obtained the lowest mean $(\underline{\mathrm{M}}=3.23, \mathrm{SD}=0.65)$, which is 
construed as Skillful. On average, leadership skill $(\underline{\mathrm{M}}=3.52, \mathrm{SD}=0.52)$ is portrayed as Very Skillful. It indicates that the leadership skills of the graduates are honed well by the school and are improved in their workplace aside from challenging people to take risks.

As to decision making, among the five indicators, the item with the highest mean is $I$ determine the factors most important to the decision, and use such to evaluate my choices $(\underline{\mathrm{M}}=3.62, \mathrm{SD}=0.50)$ and is characterized as Very Skillful, while the item that obtained the lowest mean is I take the time required to select the best decision-making tool for each specific decision $(\underline{\mathrm{M}}=3.35, \mathrm{SD}=0.63)$ which is construed as Very Skillful. On average, decision-making $(\underline{\mathrm{M}}=3.50, \mathrm{SD}=0.54)$ is described as Very Skillful. It manifests that the activities or programs provided to the graduates enhanced their decision-making skills.

As to problem-solving, among the five indicators, the item with the highest mean is $I$ maintain an attitude of openness to ideas which could help solve the problem $(\underline{\mathrm{M}}=3.85$, $\mathrm{SD}=0.37$ ), and is characterized as Very Skillful. In contrast, the item I handle problems by utmost prudence received the lowest mean $(\underline{\mathrm{M}}=3.46, \mathrm{SD}=0.71)$, construed as Very Skillful. On average, problem-solving $(\underline{\mathrm{M}}=3.70, \mathrm{SD}=0.50)$ is described as Very Skillful. It implies that their problem-solving skills improved with the different activities in school and their workplace.

As to creativity, among the five indicators, the item with the highest mean is I consult others to enhance knowledge and wisdom to be able to create new things $(\underline{\mathrm{M}}=3.65, \mathrm{SD}=0.49)$, and is illustrated as Very Skillful, while the items with the lowest mean are I provide new ideas or concepts and go beyond conditioned setups; I create and innovate alternative strategies for the improvement of the institution $(\underline{\mathrm{M}}=3.42, \mathrm{SD}=0.50)$, which are portrayed as Very Skillful. On average, creativity $(\underline{\mathrm{M}}=3.51, \mathrm{SD}=0.52)$ is described as Very Skillful. It indicates that their work and activities conducted provided them the opportunity to express their creativity.

As to human relations, among the five indicators, the item with the highest mean is I treat and value individuals with dignity as children of God $(\underline{\mathrm{M}}=3.88, \mathrm{SD}=0.33)$, which is portrayed as Very Skillful. In contrast, the item I feel comfortable with different kinds of people in my workplace obtained the lowest mean $(\underline{\mathrm{M}}=3.54, \mathrm{SD}=0.65)$, which is likewise characterized as Very Skillful. On average, human relations $(\underline{\mathrm{M}}=3.78, \mathrm{SD}=0.43)$ is illustrated as Very Skillful. It indicates that the school has trained them on the proper way of relating to others, which is true as it is reflected on the school's core values and where they practiced those values.

As to research, among the five indicators, the item with the highest mean is I continue to pursue information to gain broad perspective $(\underline{\mathrm{M}}=3.58, \mathrm{SD}=0.50)$ and is characterized as Very Skillful, while the item with the lowest mean is I conduct research and utilize the results in response to the demands of society $(\underline{\mathrm{M}}=3.12, \mathrm{SD}=0.77)$, and is portrayed as Skillful. On average, research $(\underline{\mathrm{M}}=3.36, \mathrm{SD}=0.59)$ is described as Very Skillful. It implies that their skills in the research were performed when they were in their undergraduate studies. Still, in their workplace, research is not that required. It is reflected on the result of the study, particularly on the item I conduct research and utilize the results in response to the demands of society.

On average, the exit skills of the graduates $(\underline{\mathrm{M}}=3.55, \mathrm{SD}=0.52)$ are portrayed as Very Skillful. Although there are three indicators described as Skillful, it did not affect the average of each skill and even the average of all the skills. Thus, it implies that the school has provided 
activities that enhanced their skills, and they were trained to be prepared in their careers when they graduate.

\section{Relationship between the Profile of the Participants and the Exit Skills}

Table 5 presents the significance of the relationship between the profile and the exit skills of the participants.

As to the hypothesis explaining that there is no significant relationship between the profile of the participants and their exit skills, findings revealed that the age and LET performance of the participants have no bearing with their exit skills. However, it is also presented that the sex of the participants is significantly associated with the decision making ( $\mathrm{r}=-0.45$ and $\mathrm{p}$-value $=0.0196)$. The finding displays that there is a moderately small correlation between sex and decision-making. Other skills own a very small correlation with the profile of the participants, as displayed in the statistical computations.

Table 5

Relationship Measure between the Profile of the Participants and their Exit Skills

\begin{tabular}{|c|c|c|c|}
\hline Profile & Exit Skills & $\mathrm{r}$ & p-value \\
\hline \multirow{7}{*}{ Age } & Communication Skills & -0.25 & 0.2141 \\
\hline & Leadership Skills & -0.15 & 0.4706 \\
\hline & Decision Making & -0.38 & 0.0526 \\
\hline & Problem Solving & -0.25 & 0.2139 \\
\hline & Creativity & -0.30 & 0.1309 \\
\hline & Human Relations & -0.17 & 0.4111 \\
\hline & Research & -0.29 & 0.1442 \\
\hline \multirow{7}{*}{ Sex } & Communication Skills & -0.10 & 0.6241 \\
\hline & Leadership Skills & -0.02 & 0.9199 \\
\hline & Decision Making & -0.45 & 0.0196 \\
\hline & Problem Solving & -0.38 & 0.0578 \\
\hline & Creativity & -0.12 & 0.5577 \\
\hline & Human Relations & -0.20 & 0.3390 \\
\hline & Research & -0.30 & 0.1423 \\
\hline \multirow{7}{*}{ LET Performance } & Communication Skills & 0.09 & 0.6537 \\
\hline & Leadership Skills & 0.30 & 0.1327 \\
\hline & Decision Making & -0.03 & 0.8739 \\
\hline & Problem Solving & 0.25 & 0.2131 \\
\hline & Creativity & 0.02 & 0.9047 \\
\hline & Human Relations & 0.12 & 0.5465 \\
\hline & Research & 0.14 & 0.4808 \\
\hline
\end{tabular}

Based on the statistical computations, the communication skills, leadership skills, decision making, problem solving, creativity, human relations, and research skills are not according to their age $(\mathrm{r}=-0.25,-0.15,-0.38,-0.25,-0.30,-0.17$, and -0.29 ; and $\mathrm{p}$-values $=0.2141,0.4706$, $0.0526,0.2139,0.1309,0.4111$, and 0.1442 , respectively), thus, the null hypothesis is not rejected. It indicates that the skills of a graduate do not matter as to his or her age.

From the same Table, the sex of the participants possesses a significant relationship to decision making $(\mathrm{r}=-0.45$ and $\mathrm{p}$-value $=0.0196)$, which leads to the rejection of the null hypothesis. It implies that the sex of the participants influences his/her decision-making skills. 
This finding is approved by the study of Desvaux et al. (2010) in which they discovered that one is better in decision-making than the other, and men make decisions better with executions than women. However, the sex of the participants does not bear any relationship with the other exit skills as to communication skills, leadership skills, decision making, problem-solving, creativity, human relations, and research skills $(\mathrm{r}=-0.10,-0.02,-0.38,-0.12,-0.20$, and -0.30 ; $\mathrm{p}$-values $=0.6241,0.9199,0.0578,0.5577,0.3390,0.1423$, respectively); thus, the null hypothesis is not rejected among these skills. It implies that the sex of the participants has no influence on the exit skills except on decision making.

Table 5 also presents that the communication skills, leadership skills, decision making, problem-solving, creativity, human relations, and research skills of the participants have no significant relationship to the LET performance of the graduates $(\mathrm{r}=0.09,0.30,-0.03,0.25$, $0.02,0.12$, and 0.14; and p-values $=0.6537,0.1327,0.8739,0.2131,0.9047,0.5465,0.4808$, respectively); thus, there is no significant relationship between the profile of the graduates and their exit skills. It reveals that the LET performance of the graduates has no bearing on their exit skills. It is true because LET measures the graduates' knowledge of the courses they have enrolled, which excludes the skills mentioned in this study.

In other words, decision-making is the only indicator that bears a relationship with the profile of the graduates, particularly to the sex of the participants.

\section{Relationship between the Employment Status and Exit Skills of the Graduates}

Table 6 displays the significance of the relationship between the employment status and the exit skills of the graduates.

Table 6

Relationship Measure between the Employment Status and Exit Skills of the Graduates

\begin{tabular}{llcll}
\hline $\begin{array}{l}\text { Employment } \\
\text { Characteristics }\end{array}$ & Exit Skills & $\mathrm{R}$ & $\mathrm{P}$ & Decision \\
\hline \multirow{4}{*}{ Work } & Communication Skills & -0.04 & 0.8296 & Do not reject $\mathrm{H}_{\mathrm{O} 2}$ \\
& Leadership Skills & 0.19 & 0.0344 & Reject $\mathrm{H}_{\mathrm{O} 2}$ \\
& Decision Making & 0.02 & 0.9096 & Do not reject $\mathrm{H}_{\mathrm{O} 2}$ \\
& Problem Solving & 0.21 & 0.0298 & Reject $\mathrm{H}_{\mathrm{O} 2}$ \\
& Creativity & -0.15 & 0.0444 & Reject $\mathrm{H}_{\mathrm{O} 2}$ \\
& Human Relations & 0.05 & 0.7929 & Do not reject $\mathrm{H}_{\mathrm{O} 2}$ \\
& Research & -0.04 & 0.8478 & Do not reject $\mathrm{H}_{\mathrm{O} 2}$ \\
\hline \multirow{5}{*}{ Employment Type } & Communication Skills & -0.08 & 0.6911 & Do not reject $\mathrm{H}_{\mathrm{O} 2}$ \\
& Leadership Skills & -0.07 & 0.7416 & Do not reject $\mathrm{H}_{\mathrm{O} 2}$ \\
& Decision Making & 0.28 & 0.0152 & Reject $\mathrm{H}_{\mathrm{O} 2}$ \\
& Problem Solving & 0.19 & 0.3389 & Do not reject $\mathrm{H}_{\mathrm{O} 2}$ \\
& Creativity & 0.07 & 0.7412 & Do not reject $\mathrm{H}_{\mathrm{O} 2}$ \\
& Human Relations & 0.03 & 0.8745 & Do not reject $\mathrm{H}_{\mathrm{O} 2}$ \\
& Research & 0.19 & 0.3342 & Do not reject $\mathrm{H}_{\mathrm{O} 2}$ \\
\hline \multirow{5}{*}{ Employer Type } & Communication Skills & 0.40 & 0.0401 & Reject $\mathrm{H}_{\mathrm{O} 2}$ \\
& Leadership Skills & 0.20 & 0.3244 & Do not reject $\mathrm{H}_{\mathrm{O} 2}$ \\
& Decision Making & 0.30 & 0.0278 & Reject $\mathrm{H}_{\mathrm{O} 2}$ \\
& Problem Solving & 0.39 & 0.1438 & Do not reject $\mathrm{H}_{\mathrm{O} 2}$ \\
\hline
\end{tabular}




\begin{tabular}{llll}
\hline Creativity & 0.32 & 0.1011 & Do not reject $\mathrm{H}_{\mathrm{O} 2}$ \\
Human Relations & 0.27 & 0.1816 & Do not reject $\mathrm{H}_{\mathrm{O} 2}$ \\
Research & 0.26 & 0.1926 & Do not reject $\mathrm{H}_{\mathrm{O} 2}$ \\
\hline
\end{tabular}

As to the hypothesis which asserts that there is no relationship between the employment status and the exit skills of the graduates, findings unveil that the communication skills, decision making, human relations, and research skills of the participants are not significantly associated with work $(\mathrm{r}=-0.04,0.02,0.05$, and -0.04; and $\mathrm{p}$-values $=0.8296,0.9096,0.7929$, and 0.8478 , respectively). These statistical computations produce the acceptance of the null hypothesis of no significant relationship between the employment status and the exits skills of the graduates. However, leadership skills, problem-solving, and creativity possess a significant relationship to the employment status of the graduates $(\mathrm{r}=0.19,0.21$, and -0.15 ; and $\mathrm{p}$-values= $0.0344,0.0298$, and 0.0444 , respectively); thus, the null hypothesis is rejected between the exit skills and employment status of graduates. The result is true because leadership skills are essential if somebody is willing to be productive and effective in the work (McGurgan, 2021); the ability to solve problems is critical in any work; creative thinkers can also create new views for the company.

From the same table, it is presented that the type of employment has no significant relationship to the communication skills, leadership skills, problem-solving, creativity, human relations, and research skills of the participants $(\mathrm{r}=-0.08,-0.07,0.19,0.07,0.03$, and 0.199; and $p$-values $=0.6911,0.7416,0.3389,0.7412,0.8745$, and 0.3342 , respectively); thus, the null hypothesis is not rejected between the employment status and the exits skills of the graduates. However, decision-making is significantly associated with the type of employment (the computed $\mathrm{r}$ is 0.28 and the $\mathrm{p}$-value is 0.0152 ); thus, the null hypothesis is rejected between the employment status and the exits skills of the graduates. It implies that decision-making skill depends on the type of employment of the graduate. It is true because decision making skill is beneficial to employers as they save time and money. Employees with this skill are mostly preferred by the employer and are provided high positions.

Table 6 also displays that communication and decision-making skills possess a significant relationship to the employer type $(\mathrm{r}=0.40$ and 0.30 ; and $\mathrm{p}$-values $=0.0401$ and 0.0278 , respectively), leading to the rejection of the null hypothesis between the employment status and the exits skills of the graduates. It indicates that the communication and decision-making skills of the graduates have a bearing on their employer type. The result is true because decisionmaking skills are beneficial to employers as they save time and money; employers look into how people work and communicate with others.

However, leadership skills, problem solving, creativity, human relations, and research skills of the participants have no significant relationship to employer type ( $\mathrm{r}=0.20,0.39,0.32,0.27$, and 0.26 ; and $\mathrm{p}$-values $=0.3244,0.1438,0.1011,0.1816$, and 0.1926 , respectively). The statistical computations lead to the acceptance of the null hypothesis between the employment status and the exits skills of the graduates. It signifies that exit skills, except communication and decision making, have no bearing on the employer type.

Based on the statistical computations, it unveiled that leadership skills, problem-solving, and creativity possess a significant relationship to work; decision making is significantly 
associated with the type of employment; communication skills and decision making have a significant relationship to the employer type.

\section{Exit Skills as Predictors for Employability of Graduates}

Table 7 presents the regression model for the predictors of employability. The exit skills were implemented as predictors of the employability of the graduates.

The researchers employed Multiple Linear Regression Analysis to identify the predictors for the graduates' employment.

Table 7

Regression Model for the Predictors of Employability

\begin{tabular}{|c|c|c|c|c|c|c|c|}
\hline $\begin{array}{l}\text { Dependent } \\
\text { Variable }\end{array}$ & Predictors & BETA & $\begin{array}{c}\text { St. Err. } \\
\text { of BETA }\end{array}$ & $\beta$ & $\begin{array}{c}\text { St. Err. } \\
\text { of } \beta\end{array}$ & p-level & $\begin{array}{l}\text { Adjust } \\
\text { ed } \mathrm{R}^{2}\end{array}$ \\
\hline \multirow{4}{*}{ Work } & Constant & & & -0.32 & 2.50 & 0.8983 & \multirow{4}{*}{0.1519} \\
\hline & Problem Solving & 0.61 & 0.25 & 2.25 & 0.93 & 0.0226 & \\
\hline & Creativity & -0.58 & 0.25 & -1.84 & 0.80 & 0.0298 & \\
\hline & Leadership Skills & 0.24 & 0.23 & 0.88 & 0.86 & 0.3156 & \\
\hline \multirow{2}{*}{$\begin{array}{l}\text { Employment } \\
\text { Type }\end{array}$} & Constant & & & -0.62 & 1.61 & 0.7042 & \multirow{2}{*}{0.0402} \\
\hline & Decision Making & 0.28 & 0.19 & 0.67 & 0.46 & 0.1520 & \\
\hline \multirow{3}{*}{$\begin{array}{l}\text { Employer } \\
\text { Type }\end{array}$} & Constant & & & -1.31 & 1.07 & 0.2323 & \multirow{3}{*}{0.1484} \\
\hline & Communication Skills & 0.36 & 0.18 & 0.51 & 0.26 & 0.0639 & \\
\hline & Decision Making & 0.24 & 0.18 & 0.27 & 0.21 & 0.2033 & \\
\hline
\end{tabular}

The statistical computations display that problem solving, creativity, and leadership skills are predictors for work (adjusted $\mathrm{R}^{2}=0.1519$ and $\mathrm{p}$-values $=0.0226,0.0298$, and 0.3156, respectively). The three predictors were able to account for $15.19 \%$ of the variance in the employment status of the graduates in terms of work. These three skills are considered predictors because the adjusted $\mathrm{R}^{2}$ produced by the statistical tool is an indicator of whether the variable/s (exit skills) is/are to be considered as predictors or not. It also indicates that among the seven exit skills, problem-solving, creativity, and leadership skills possess the highest adjusted $\mathrm{R}^{2}$, which is the basis for a variable to be a predictor. The computation of the predictor for work supports Table 5 on the significant relationship of leadership skills, problem-solving, and creativity to work. There is a significant relationship between these three skills and work, and these skills are also as predictors for work.

As displayed in Table 7, the problem-solving and leadership skills owned considerable positive regression weights, which indicates that participants with higher scores on these skills were expected to have higher employability after controlling for the other variables in the model. The creativity skill possesses a significant negative weight (opposite in sign from its correlation with the criterion), which implies that those participants with higher creativity scores were expected to have lower employability (a suppressor effect).

Leadership skill is considered as one of the predictors for work because it is essential to be productive and effective. Being knowledgeable about the work is not enough, but one must also share knowledge with the people in the workplace (Leviticus, 2016). 
Rihal (2017) argued that effective leadership is established upon a solid foundation with a clear mission, a vision for the future, a specific strategy, and a culture conducive to success. Hence, it is a crucial skill required in the workplace. Moreover, leadership was considered a basis element for a well-coordinated and integrated provision of care, both from the patients and healthcare professionals (Sfantou et al., 2017).

One of the first research to empirically rank-order skill demand is the study of Rios et al. (2020). They discovered that in high demand skills by the employers include oral and written communication, collaboration, and problem-solving skills, with particular emphasis on the pairing of oral and written communication. Their study emphasized that problem-solving skill is one of in-high demand skills required by employers in which it is considered a predictor in the present study.

Soft skills like creativity, empathy, judgment, and the ability to motivate others, as Chui, Manyika and Miremadi (2015) discovered, remain unique to humans. Creative thinkers tend to create new ways of conducting things as they are innovative. These are added value to the work environment, making systems and procedures more efficient and effective. One will land a work that requires creativity if he/she is creative. It is the reason why creativity is a predictor for work.

It is also presented in Table 6 that decision-making is a predictor for the employment type (adjusted $\mathrm{R}^{2}=0.0402$ and $\mathrm{p}$-value=0.1520). It implies that decision-making is one of the skills that employers consider as the worker's employment type. The decision-making skill possessed significant positive regression weight, which indicates that participants with higher scores on this skill were expected to own higher employability after controlling for the other variables in the model. The result for the predictors of the employment type supports Table 6 on the significant relationship of decision making to the type of employment. There is a significant relationship between decision-making and employment type, and this skill is also a predictor for the employment type.

Table 7 also displays that communication skills and decision-making are the predictors for the variable employer type (adjusted $\mathrm{R}^{2}=0.1484$, $\mathrm{p}$-values $=0.0639$, and 0.2033 , respectively.) The communication and decision-making skills owned significant positive regression weights, that indicates that participants with higher scores on these skills were expected to have higher employability after controlling for the other variables in the model. Findings on the predictor for the type of employer support the result in Table 6 on the significant relationship of communication skills and decision making to the employer type. There is a significant relationship between communication skills and decision making and the type of employer, and these skills are also predictors for the employer type.

The result corroborates with the findings of Suarta et al. (2017), in which they discovered that communication, problem-solving and decision-making, and teamwork skills are employability skills with the highest importance level.

Decision-making is considered a predictor for employment and employer type because it is crucial in the workplace and for employers to save time and money. It also requires the recording of information that can be referred to when planning future projects.

Good communication skills help ensure that staff members understand the instructions and expectations. Hold regular meetings with the staff to discuss progress on projects, 
achievements, and departmental, and company news (Leviticus, 2016). It is the reason why communication skill is a predictor for the employer type.

\section{Conclusion}

Based on the findings revealed in this study, the researcher concluded that most of the Bachelor of Secondary Education major in Mathematics graduates from 2005-2015 are females and LET passers and teachers in a public institution. The exit skills of the graduates are characterized as Very Skillful, which indicates that they were able to effectively employ the skills acquired from the school to their workplace. Decision-making is the only skill that bears a relationship with the profile of the graduates, particularly sex. Leadership skills, problemsolving, and creativity possess a significant relationship to work. Decision-making is significantly associated with the type of employment. Communication skills and decisionmaking possess a significant relationship to the employer type. The skills such as problemsolving, creativity, leadership skills, communication, and decision-making are predictors of the employability of the graduates. On the other hand, human relations and research are nonpredictors of employability. Therefore, the exit skills of the graduates are the predictors of employability.

Based on the conclusions, the researchers recommend that the school creates programs and activities to enhance students' skills, particularly problem-solving, creativity, leadership skills, communication, and decision-making, which are considered predictors of employability. They may focus on the non-predictors of employability, specifically human relations, and research, because these skills are still required in the workplace, particularly on the part of the teachers. Since the study focuses merely on the Exit Skills as Predictors of Employability of the Bachelor of Secondary Education major in Mathematics Graduates, it is recommended to the future researchers to expand this study by encompassing (1) Exit Skills as Predictors of Employability of the Teacher Education Graduates; and Employment Status and LET Performance of the Education Graduates.

\section{Acknowledgments}

We wish to convey our heartfelt gratitude to the graduates of Bachelor of Secondary Education major in Mathematics of St. Paul University Surigao, batches 2005-2015 for their participation in the conduct of the study. We would also like to thank St. Paul University Surigao for allowing us to conduct this study, along with the administration, faculty and staff.

\section{References}

Boholano, H. B. (2012). Employability of teacher education graduates of an asian public university. JPAIR Multidisciplinary Research, 9 (1). https://doi.org/10.7719/jpair.v9i1.12

Cardona, R., \& Andres, E. M. (2014). The employability of mathematics education graduates (2008-2013) of a teacher education institution (Tei) in the Philippines. Researchers World, $5,146$. 
Carr, L. (2016). What are achievements in job applications. Retrieved from: https://www.sapling.com/8034458/achievements-job-applications

Chui, M., Manyika, J., \& Miremadi, M. (2015). Four fundamentals of workplace automation. The McKinsey Quarterly, 29(3), 1-9.

Desvaux, G., Devillard, S., Sultan, S. (2010). Women leaders: A competitive edge in and after the crisis. McKinsey \& Company. https://www.mckinsey.com/ /media/mckinsey/business\%20functions/organization/our\% 20insights/women\%20matter/women_matter_dec2009_english.ashx

Frost, J. (2013). Regression analysis: How do i interpret $r$-squared and assess the goodnessof-fit? The Minitab Blog Website. http://blog.minitab.com/blog/adventures-instatistics/regression-analysis-how-do-iinterpret-r-squared-and-assess-the-goodness-of-fit

Knight, P., \& Yorke, M. (2003). Assessment, learning, and employability. Society for Research into Higher Education \& Open University Press. http://193.1.88.47/careers/units/unitce028.shtml

Leviticus, J. (2016). Communication \& leadership in the workplace. CHRON. http://work.chron.com/communication-leadership-workplace-14761.html

McGurgan, H. (2021). Communication \& leadership in the workplace. CHRON. http://work.chron.com/communication-leadership-workplace-14761.html

Rihal, C. S. (2017). The importance of leadership to organizational success. NEJM Catalyst, 3(6).

Rios, J. A., Ling, G., Pugh, R., Becker, D., \& Bacall, A. (2020). Identifying critical 21st-century skills for workplace success: A content analysis of job advertisements. Educational Researcher, 49(2), 80-89.

Sfantou, D. F., Laliotis, A., Patelarou, A. E., Sifaki-Pistolla, D., Matalliotakis, M., \& Patelarou, E. (2017). Importance of leadership style towards the quality-of-care measures in healthcare settings: a systematic review. Healthcare Volume 5 No. 4 (pp. 73). Multidisciplinary Digital Publishing Institute.

Suarta, I. M., Suwintana, I. K., Sudhana, I. F. P., \& Hariyanti, N. K. D. (2017). Employability skills required by the 21 st century workplace: A literature review of labor market demand. In International Conference on Technology and Vocational Teachers (ICTVT 2017). Atlantis Press.

Wuencsch, K. (2014). Stepwise Regression. NCSS. https://ncss-wpengine.netdna-ssl.com/wpcontent/themes/ncss/pdf/Procedures/NCSS/Stepwise_Regression.pdf 